\title{
ANN Based Prediction of Engine Performance and Exhaust Emission Responses of a CI Engine Powered by Ternary Blends
}

\author{
Mustafa Karagöz \\ 0000-0002-2595-9002 \\ ${ }^{1}$ Mechanical Engineering Department, Faculty of Mechanical, Karabuk University, Karabük, 78050, Turkey
}

\begin{abstract}
In this study, experimental data was collected from a single cylinder diesel engine fueled by pyrolytic oil, neat diesel and butanol fuel blends. The experiments were conducted at various engine loads, namely from $0.25 \mathrm{~kW}$ to $1.25 \mathrm{~kW}$ by $0.25 \mathrm{~kW}$ increment. The engine performance and exhaust emission data obtained were modeled using an artificial neural network (ANN) algorithm. $\mathrm{CO}, \mathrm{NO}_{\mathrm{x}}$, BSFC, and BTE were considered in the ANN model. The results were discussed in terms of $\mathrm{R}^{2}$, MBE, and RMSE metrics. $\mathrm{R}^{2}$ value of the performance and exhaust emission responses' prediction were 0.986, 0.963, 0.991, and 0967 for BTE, $\mathrm{BSFC}, \mathrm{NO}_{\mathrm{x}}$, and $\mathrm{CO}$, respectively, and in addition, all MBE value was very close to zero and smaller than 1.14. As a conclusion, the present paper showed that performance and exhaust emission responses of ternary fuels can be accurately predicted using an artificial neural network
\end{abstract}

Keywords: Artificial neural network, pyrolytic oil, butanol, diesel, ternary fuel, diesel engine

\begin{abstract}
* Corresponding author
Mustafa KARAGÖZ

Mustafakaragoz@karabuk.edu.tr

Adress: Mechanical Engineering Department, Faculty of Mechanical, Karabuk University,

Karabük, 78050, Turkey
\end{abstract}

Tel: $+90(370) 4187202$

Fax: +90 (370) 4189345

Researh Article

\begin{tabular}{ll} 
Manuscript & \\
Received & 20.07 .2020 \\
Revised & 30.08 .2020 \\
Accepted & 01.09 .2020 \\
\hline
\end{tabular}

Doi: 10.30939/ijastech..771789

\section{Introduction}

Despite the increasing number of vehicles in the world, the decrease in the reserves of primary energy sources and increasing emission standards for vehicles have accelerated the search for alternative fuels. Fuels such as electrical energy, hydrogen, bio diesels, alcohol based fuels, biogas, liquid petroleum gas and compressed natural gas are used as alternative fuels in internal combustion engines and studies are carried out on these fuels. Quality criteria expected from alternative fuels can be listed as sustainability, accessibility, performance and compliance with emission standards. In order to ensure sustainability and to be more environmentally friendly, the evaluation of wastes as fuel (energy from waste) makes energy from waste more attractive in alternative fuels [1-3]. Energy can be regained from garbage, wastewater, factory waste, animal manure and many other worthless process products. One of these wastes is used tires. Problems such as used vehicle tires occupying a lot of space in the storage yards and causing environmental pollution, indissolubility in nature, increasing the risk of fire, making millions of tires become waste in the world every year makes it necessary to evaluate waste tires.

Waste tires can be used as fuel in internal combustion engines by pyrolysis method [4]. Doğan et al. 2012, Wang et al. 2016, Adam et al. 2017, Murugan et al. 2008, Frigo et al. 2014, Karagöz, et al. 2020, in their studies, they examined the use of pyrolytic fuel from waste tires in internal combustion engines [4-9]. Researchers reported that pyrolytic fuel obtained from waste tires showed similar properties to diesel fuel. Besides, the researchers stated that with the addition of pyrolytic fuel to diesel fuel, some emission values improved while $\mathrm{NO}_{\mathrm{x}}$ emission increased. Doğan 2011, Yusri et al. 2019, 
carried out experiments on internal combustion engines by adding butanol to diesel fuel and emphasized that fuels containing high levels of oxygen have the potential to significantly reduce $\mathrm{NO}_{\mathrm{x}}$ emissions [10,11]. In obtaining the experimental data of the subject study, it was aimed to improve $\mathrm{NO}_{\mathrm{x}}$ emissions by adding butanol to the diesel pyrolytic fuel mixture.

Internal combustion engine tests, in which alternative fuels are tested, are complex, difficult and expensive processes where the engine, dynamometer units, many sensors, analyzers and thermocouples have to be used together. Instead of doing all the steps of expensive and time consuming engine tests, some of the test results can be used for training and the results of the untested parts can be predicted by using estimation methods. ANN, one of these estimation methods, is frequently used in engineering due to its high accuracy and simple use. With the well-trained ANN algorithm, the engine responses can be accurately predicted in a short time [12].

Based on the ANN studies in the recent literature, it can be said that generally predictability of exhaust emissions (HC, $\mathrm{CO}, \mathrm{NO}_{\mathrm{x}}$ ) [13-15], performance (BTE (Brake Thermal Efficiency), BSFC (Brake Specific Fuel Consumption) [13-16], and combustion $\left(\mathrm{CP}_{\max }\right)$ characteristics $[13,17,18]$, for various test fuels was tested. For example, Ağbulut et al., 2020b predicted CPmax, BSFC, $\mathrm{CO}, \mathrm{HC}$ and $\mathrm{NO}_{x}$ parameters by using an ANN algorithm for various test fuels, different engine loads and different injection pressures in a diesel engine [19].

In this study, experiments were carried out in a diesel engine using diesel - pyrolytic fuel - butanol fuel mixture. From the experimental data obtained, an ANN based prediction has been performed using engine load and test fuel as input parameters and effective efficiency, specific fuel consumption, $\mathrm{CO}$ and $\mathrm{NO}_{\mathrm{x}}$ as output parameters.

\section{Materials and Methods}

\subsection{Test Fuels and Test Engine}

The fuels used in the tests were created by volumetric blending of pyrolytic fuel, diesel and butanol. Volumetric content and abbreviations of test fuels are given in Table 1. The triple fuel mixture was kept in the magnetic mixer for 15 minutes to ensure homogeneity. Diesel engine-generator set was used in the experiments. In the study, a single cylinder, 18:1 compression ratio, $7.8 \mathrm{~cm}$ cylinder diameter, $6.2 \mathrm{~cm}$ stroke, direct injection, air cooled engine was used. $4 \mathrm{~kW}$ of power can be obtained from the engine at $3000 \mathrm{rpm}$. The tests were started when the engine temperature stabilized and three repetition were averaged for each fuel and load condition. Experiments were carried out at four different loads of
$0.50,0.75,1.00$ and $1.25 \mathrm{~kW}$ to examine the operating conditions of the engine under different load conditions. The tests were performed at a constant 3000 engine speed. The fuel consumption of the engine was measured in mass with precision scales. Exhaust emission measurements were carried out with Bilsa brand exhaust emission analyzer. The schematic view of the experimental test rig is shown in Figure 1. The properties of test fuels are given in Table 2 [20].

Table 1. Test fuels, blending-percentages and abbreviations

\begin{tabular}{cccccccc} 
& & \multicolumn{5}{c}{ Test Fuel (TF)- Abb. } \\
\cline { 2 - 7 } & & TF1 & TF2 & TF3 & TF4 & TF5 & TF6 \\
\hline \multirow{2}{*}{$\overbrace{0}^{\circ}$} & Pyrolytic oil & 0 & 15 & 15 & 15 & 30 & 45 \\
\cline { 2 - 7 } & n-Butanol & 0 & 5 & 10 & 15 & 15 & 15 \\
\hline \multirow{2}{*}{ Neat diesel } & 100 & 80 & 75 & 70 & 55 & 40 \\
\hline
\end{tabular}

Table 2. Some important fuel properties.

\begin{tabular}{ccccc}
\cline { 2 - 5 } & \multicolumn{4}{c}{ Property } \\
\cline { 2 - 6 } & $\begin{array}{c}\text { Density } \\
\left(\mathrm{kg} / \mathrm{m}^{3} ;\right. \\
\left.15^{\circ} \mathrm{C}\right)\end{array}$ & $\begin{array}{c}\text { Cetane } \\
\text { number }\end{array}$ & $\begin{array}{c}\text { Viscosity, } \\
(\mathrm{cSt} \\
\left.\text { @ } 40^{\circ} \mathrm{C}\right)\end{array}$ & $\begin{array}{c}\text { Lower } \\
\text { heating } \\
\text { value } \\
(\mathrm{MJ} / \mathrm{kg})\end{array}$ \\
\hline $\mathrm{TF} 1$ & 835.00 & 54.92 & 2.929 & 45.94 \\
\hline $\mathrm{TF} 2$ & 843.40 & 51.19 & 2.776 & 44.54 \\
\hline $\mathrm{TF} 3$ & 842.20 & 49.69 & 2.740 & 43.90 \\
\hline $\mathrm{TF} 4$ & 841.00 & 48.19 & 2.703 & 43.26 \\
\hline TF5 & 850.60 & 45.96 & 2.587 & 42.50 \\
\hline TF6 & 860.20 & 43.72 & 2.470 & 41.74 \\
\hline Test & TS EN ISO & EN ISO 5165 & TS 1451 EN \\
Method & 12185 & TS EN 15195 3104 & EN 5165 \\
\hline & & & &
\end{tabular}

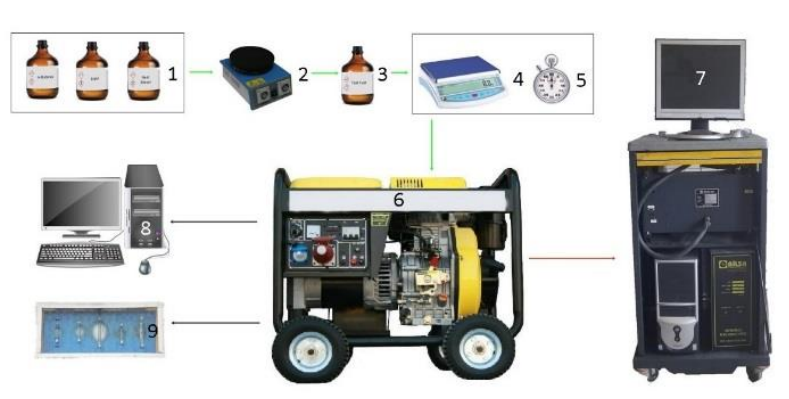

\begin{tabular}{|c|l|c|l|}
\hline 1 & $\begin{array}{l}\text { Neat diesel, n- butanol, py } \\
\text { rolytic fuel }\end{array}$ & 2 & Magnetic stirrer \\
\hline 3 & Test fuel & 4 & Precision scales \\
\hline 5 & Timekeeper & 6 & Test engine \\
\hline 7 & Exhaust analyzer & 8 & Data logger and computer \\
\hline 9 & Engine loading set & & \\
\hline
\end{tabular}

Fig. 1. Schematic view of the experimental rig. 


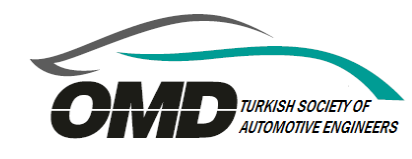

In the study, brake specific fuel consumption was calculated using Eq. 1., and brake thermal efficiency was also calculated using Eq. 2 [3].

$B S F C=\frac{\dot{m}_{f} 10^{3}}{P_{e}}$

$B T E=\frac{1000 * 3600}{B S F C * L H V}$

Where $\dot{m}_{f}$ is fuel mass consumption and it's unit is $\mathrm{kg} / \mathrm{h}$, $\mathrm{P}_{\mathrm{e}}$ is the brake effective power and it's unit is $\mathrm{kW}$, LHV is lower heating value and it's unit is $\mathrm{kJ} / \mathrm{kg}$.

\subsection{Artificial Neural Network}

ANN is probably the most frequently used tool for modeling the experimental responses, particularly with non-linear relationships both for regression and classification problems. ANN is a network structure and it consists of some process capability elements called neurons. However, the neural network structure model requires to be trained to set a nexus between inputs and responses. With this viewpoint, the mechanism of ANN is very similar to that of the human brain. After a well-done training process, the ANN algorithms is able to produce quick and reliable results even for the datasets containing missing data. Depending on the size of the networks, the number of layers may also grow to ANN. This case may result in memorizing for the network. Therefore, it is of great importance to find the optimum network size by avoiding both this situation and waste-training time. In this paper, the ANN used a feed-forward neural network and trained by the aid of the back-propagation algorithm (multi-layer perceptron) for all responses, and the optimum network size was found with trial and error for each engine response. Fig. 2 shows the ANN structure used in the present investigation.

In this study, an training of ANN has been performed with backpropagation algorithm and using 24 data from the experimental results. The dataset was randomly divided into two parts: training and testing data. $80 \%$ of all dataset was used for the training of algorithm, while the remaining $20 \%$ was used for the testing data. The LM learning algorithm was solved by a hidden layer of a small number of neurons. The grid search technique is used to tune the model parameters in this study. In the study, the optimum ANN network architecture in the prediction of $\mathrm{BTE}, \mathrm{BSFC}, \mathrm{NO}_{\mathrm{x}}$ and $\mathrm{CO}$ responses have been found to be 2-7-1, 2-4-1, 2-2-1 and 2-4-1, respectively.

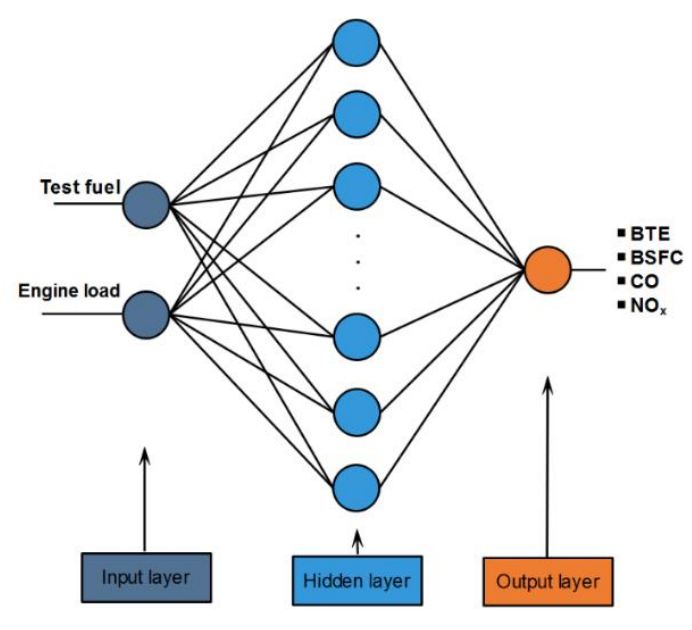

Fig.

Schematic view of ANN structure.

\subsubsection{Evaluation Metrics}

In the study, three metrics are used to discuss the performance of the prediction results. These are $\mathrm{R}^{2}$, RMSE and MBE. Table 3 gives the equations and desired cases of these metrics $[19,21,22]$.

Table 3. Equation and desired cases of the metrics.

\begin{tabular}{ccc}
\hline Metrics & Equation & \multicolumn{1}{c}{ Desired case } \\
\hline $\mathrm{R}^{2}$ & $1-\frac{\sum\left(y_{i}-x_{i}\right)^{2}}{\sum\left(x_{i}-\bar{x}_{i}\right)^{2}}$ & $\begin{array}{l}\mathrm{R}^{2} \text { is varying from } 0 \\
\text { to } 1 . \text { To be closest } \mathrm{t} \\
\text { o the zero is the idea } \\
1 \text { case [21, 22]. }\end{array}$ \\
\hline *MBE & $\frac{1}{n} \sum_{i=1}^{n}\left(y_{i}-x_{i}\right)$ & $\begin{array}{l}\text { To be closest to the } \\
\text { zero is the ideal case } \\
\text { [21, 22]. }\end{array}$ \\
\hline **RMSE & $\sqrt{\frac{1}{n} \sum_{i=1}^{n}\left(y_{i}-x_{i}\right)^{2}}$ & $\begin{array}{l}\text { To be closest to the } \\
\text { zero is the ideal case } \\
\text { [21, 22]. }\end{array}$ \\
\hline
\end{tabular}

* MBE: Mean bias error, **Root mean squared error

In Table 3, $y_{i}$ and $x_{i}$ are predicted and measured engine responses, respectively; $\bar{x}_{i}$ is the mean of measured engine response; $\mathrm{n}$ is the number of observations.

\section{Result and Discussions}

In the present investigation, the engine responses (performance and emission characteristics) are predicted with ANN algorithm. Three metrics ( $\mathrm{R}^{2}, \mathrm{RMSE}$ and MBE) are discussed to evaluate the prediction performance in the study. A summary of the prediction results is given in Table 4. As can be seen from Table 4, all responses have very satisfied results in terms of prediction side. That is, $\mathrm{R}^{2}$, RMSE and MBE are varying from 0.963 to 0.991 , from 0.019 to 19.968 and from 0.014 to 1.1356 , respectively. 


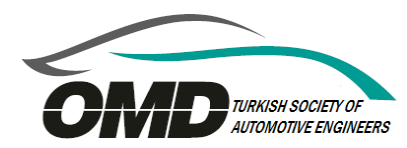

Table 4. Numerical results of evaluation metrics.

\begin{tabular}{c|c|c|c}
\multirow{2}{*}{ Response } & \multicolumn{3}{|c}{ Metrics } \\
\cline { 2 - 4 } & $\mathrm{R}^{2}$ & RMSE & MBE \\
\hline $\mathrm{BTE}$ & 0.986 & 0.174 & 0.0837 \\
\hline $\mathrm{BSFC}$ & 0.963 & 17.968 & 0.084 \\
\hline $\mathrm{NO}_{\mathrm{x}}$ & 0.991 & 9.642 & 1.1356 \\
\hline $\mathrm{CO}$ & 0.967 & 0.019 & 0.014
\end{tabular}

Figure 3 shows the curves of the data both measured and predicted for each response. As can be seen from Fig. 3, $\mathrm{NO}_{\mathrm{x}}$ gives the worst results in terms of MBE metric, even if the prediction curve is closely followed to actual data owing to its high $\mathrm{R}^{2}$ value of 0.991 . As mentioned above, the best result for MBE metric is seen at the values of closing to zero [21]. That is why BTE has the best MBE result of 0.0837 . This case is also supporting the $\mathrm{R}^{2}$ and RMSE values of
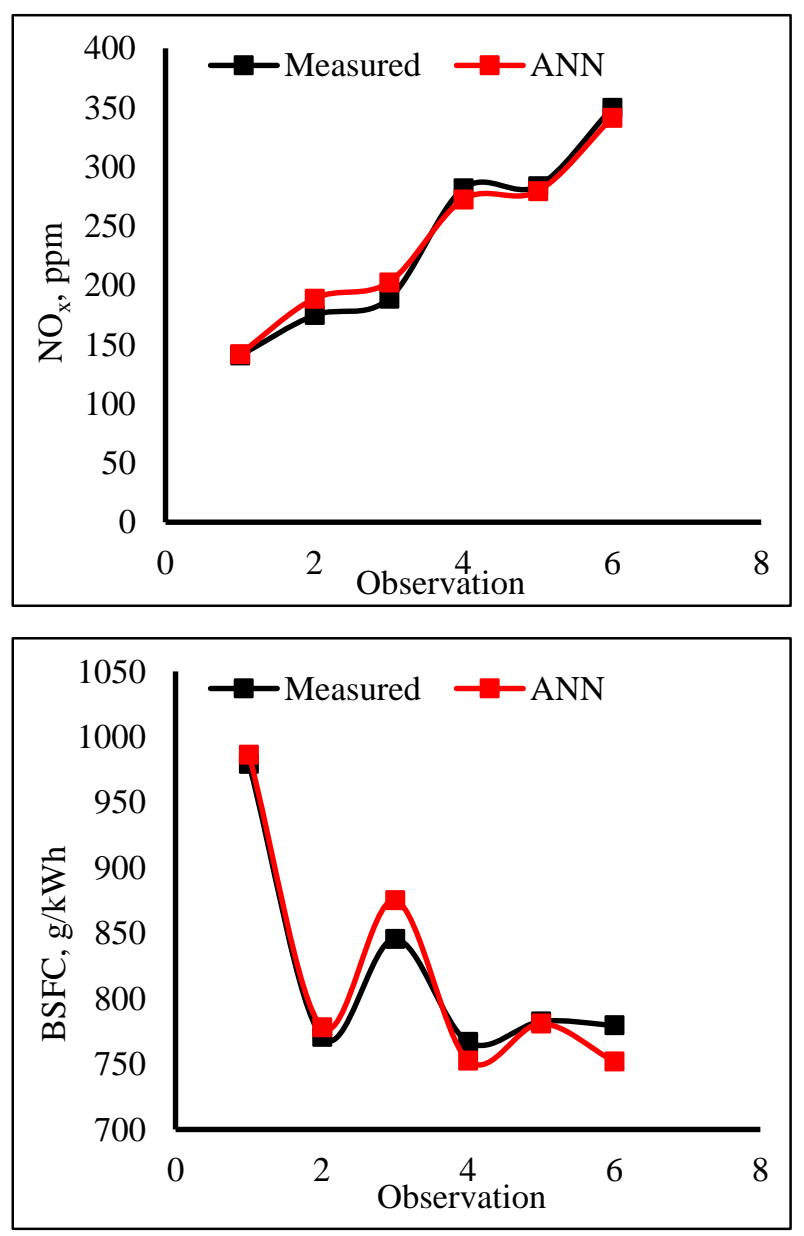

0.986 and 0.174 for BTE, respectively. On the other hand, BSFC has the worst RMSE result of 17.968. Among all responses, the worst $\mathrm{R}^{2}$ value is seen with 0.963 for RMSE even if it is very-satisfied result. In terms of $\mathrm{R}^{2}$ metric, the most successful engine response is $\mathrm{NO}_{\mathrm{x}}$. The $\mathrm{R}^{2}$ value of $\mathrm{NO}_{\mathrm{x}}$ is 0.991 . As well-known, MBE value can take positive or negative results. If $\mathrm{MBE}$ value is positive, then it means that mean of predicted values is higher than that of actual values. If it is negative, it means that mean of predicted values is smaller than that of actual values [22]. With this viewpoint, all results in terms of MBE metric are positive and varied from 0.014 to 1.1356 (See Table 4). CO emission is giving the most successful results in terms of MBE with the value of 0.014 among all responses. The worst one for MBE metric is $\mathrm{NO}_{\mathrm{x}}$ with the value of 1.1356 .
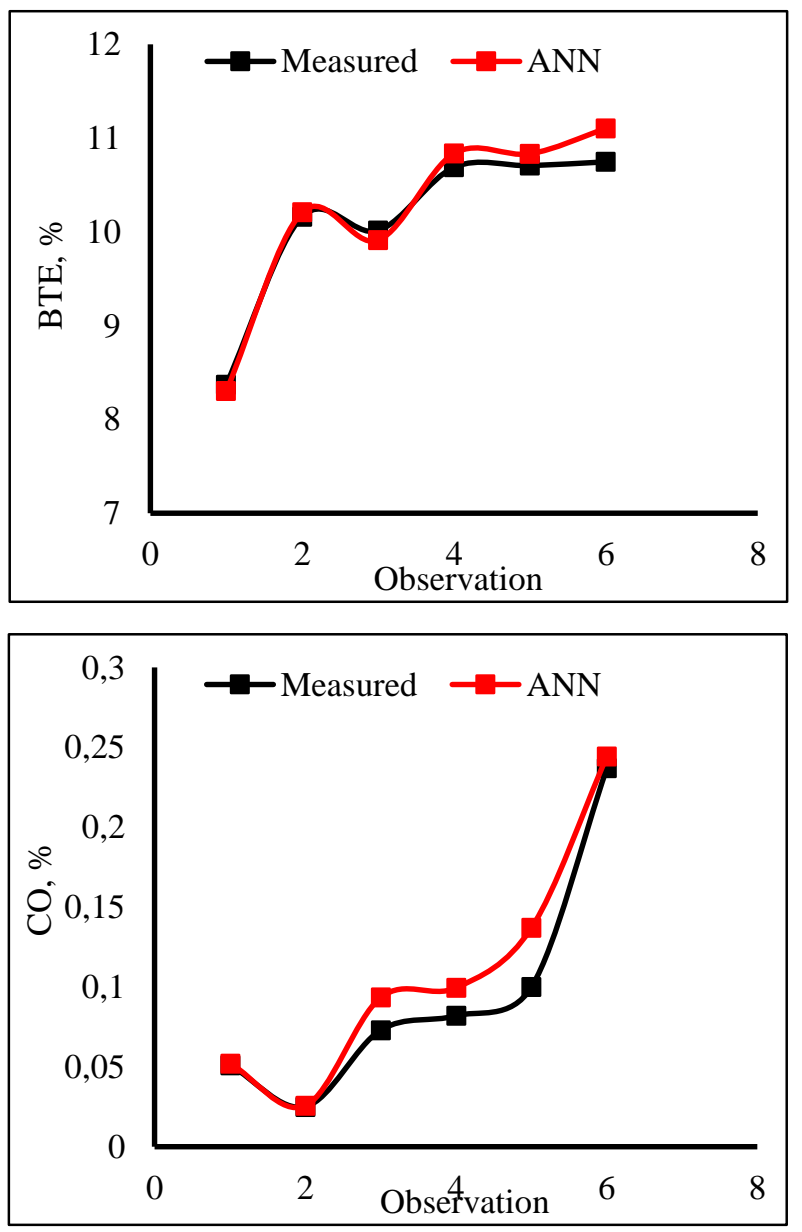

Fig. 3. Prediction results a) $\mathrm{NO}_{\mathrm{x}}$ b) BTE c) BSFC and d) $\mathrm{CO}$ 


\section{Conclusion}

In this study, experiments were carried out on a diesel engine using diesel - pyrolytic fuel - butanol fuel mixture. From the experimental data obtained, estimates were made with an artificial neural network used as engine load and test fuel as input parameters and brake thermal efficiency, specific fuel consumption, $\mathrm{CO}$ and $\mathrm{NO}_{\mathrm{x}}$ as output parameters. The following conclusions can be drawn from this study:

-The coefficient of determination for all responses is varying from $96.3 \%$ and $99.1 \%$.

-The LM learning algorithm presented very satisfying results to train the neural network advanced and for evaluating the performance of the diesel engine.

-MBE values except for $\mathrm{NO}_{\mathrm{x}}$ are found to be very close to zero. The biggest MBE value is calculated to be 1.1356 in NOx and even this value is the very-satisfying result.

-Based on the prediction results, the engine response can be successfully predicted using an artificial neural network.

\section{References}

[1] Ağbulut, Ü., Sarıdemir, S., Karagöz, M.,. (2020). Experimental investigation of fusel oil (isoamyl alcohol) and diesel blends in a CI engine. Fuel. 267, 117042.

[2] Ağbulut, Ü., Sarıdemir, S., Albayrak, S. (2019). Experimental investigation of combustion, performance and emission charac-teristics of a diesel engine fueled with diesel-biodiesel-alcohol blends. Journal of the Brazilian Society of Mechanical Sciences and Engineering. 41(9), 389.

[3] Ağbulut, Ü., Karagöz, M., Sarıdemir, S., Öztürk, A., (2020). Impact of various metal-oxide based nanoparticles and biodiesel blends on the combustion, performance, emission, vibration and noise characteristics of a CI engine. Fuel. 270, 117521.

[4] Karagöz, M., Ağbulut, Ü., Sarıdemir, S., (2020) Waste to energy: Production of waste tire pyrolysis oil and comprehensive analysis of its usability in diesel engines, Fuel, 275; 117844.

[5] Doğan, O., Çelik M. B., Özdalyan, B., (2012). The effect of tire derived fuel/diesel fuel blends utilization on diesel engine performance and emissions. Fuel. 95, 340-346.

[6] Wang, W. C., Bai, C. J., Lin, C. T., Prakash, S. (2016). Alternative fuel produced from thermal pyrolysis of waste tires and its use in a DI diesel engine. Applied Thermal Engineering. 93, 330-338.

[7] Adam, A., Ramlan, N, A., Jaharudin, N, F., Hamzah, H., Othman, M, F., Mrwan, A., A., G., (2017). Analysis of combustion characteristics, engine performance and exhaust emissions of diesel engine fueled with upgraded waste source fuel. International Journal of Hydrogen Energy. 42, 17993-18004.

[8] Murugan, S., Ramaswamy, M. C., Nagarajan, G. (2008). The use of tyre pyrolysis oil in diesel engines. Waste management. 28 (12), 2743-2749.
[9] Frigo, S., Seggiani, M., Puccini, M., Vitolo, S. (2014). Liquid fuel production from waste tyre pyrolysis and its utilization in a Diesel engine. Fuel. 116,399-408.

[10] Doğan, O., 2011. The influence of n-butanol/diesel fuel blends utilization on a small diesel engine performance and emissions. Fuel. 90, 2467-2472.

[11] Yusri, I., M., Mamat, R., Akasyah, M., K., Jamlos, M., F., Yusop, A., F., (2019). Evaluation of engine combustion and exhaust emissions characteristics using diesel/butanol blended fuel. Applied Thermal Engineering. 156, 209-219.

[12] Kurtgoz, Y., Karagoz, M., Deniz, E., (2017). Biogas engine per-formance estimation using ANN. Engineering Science and Technology, an International Journal. 20, 1563-1570.

[13] Joshi, M., P., Thipse, S., S., (2019). Combustion analysis of a compression-ignition engine fuelled with an algae biofuel blend and diethyl ether as an additive by using an artificial neural network. Biofuels,1-10.

[14] Rao, K., P., Babu, T., V., Anuradha, G., Rao, B., A., (2017). IDI diesel engine performance and exhaust emission analysis using biodiesel with an artificial neural network (ANN). Egypt J Petrol. 26(3), 593-600.

[15] Karthickeyan, V., Balamurugan, P., Rohith, G., Senthil, R., (2017). Developing of ANN model for prediction of performance and emission characteristics of VCR engine with orange oil biodiesel blends. Journal of the Brazilian Society of Mechanical Sciences and Engineering. 39 (7), 2877-88.

[16] Madane, P., Panua, R., (2019). Investigation of performance of jatropha oil on diesel engine using artificial neural network model. International Journal Computational Intelligence IOT. 2 (2).

[17] Noor, C., W., M., Mamat, R., Najafi, G., Bakar, A., A., Samo, K., (2019). Determination of bio-diesel engine combustion pressure using neural network-based model. Journal of Engineering Science and Technology. 14(2), 909-21.

[18] Gürgen, S., Ünver, B., Altın, İ., (2018). Prediction of cyclic variability in a diesel engine fueled with $\mathrm{n}$-butanol and diesel fuel blends using artificial neural network. Renewable Energy. 117, 538-544.

[19] Ağbulut, Ü., Ayyıldız, M., Sarıdemir, S., (2020). Prediction of performance, combustion and emission characteristics for a CI engine at varying injection pressures. Energy. 197, 117257.

[20] MERCK. Product specification; 2019 [in Turkish].

[21] Gürel, A. E., Ağbulut, Ü., \& Biçen, Y. (2020). Assessment of machine learning, time series, response surface methodology and empirical models in prediction of global solar radiation. Journal of Cleaner Production, 122353.

[22] Ağbulut, Ü., Gürel, A. E., \& Biçen, Y., (2021). Prediction of daily global solar radiation using different machine learning algorithms: Evaluation and comparison. Renew. and Sust. Energy Rev., 135, 110114. 